\title{
The Relationship Between Commitment-Based Human Resource Management Practices and Employee Satisfaction
}

\author{
Xiaoying Yang ${ }^{\mathrm{a}}$, Yuanyuan Liu ${ }^{\mathrm{b},{ }^{*}}$ \\ School of Economics and Management, Beijing Jiaotong \\ University, Beijing 100044, China \\ a19120721@bjtu.edu.cn, b17120702@bjtu.edu.cn \\ ${ }^{*}$ Corresponding author
}

\begin{abstract}
Keywords: commitment-based human resource management practices, employee satisfaction, quality of leader-member exchange relationship
\end{abstract}

\begin{abstract}
In the era of knowledge economy where "knowledge" is gradually replacing "capital", knowledge resources have become a vital production factor. Knowledge is intangible, but human resources with knowledge and ability are tangible and effective. The effective management of human resources has become a key factor in the success of enterprises. This paper explores the relationship between the commitment-based human resource management practices and employee satisfaction by introducing the leader-member exchange relationship as a mediator. Through empirical analysis, the following conclusions are drawn: first, the commitment-based human resource management practices have a positive impact on the employee satisfaction; secondly, the quality of the leader-member exchange relationship has played a partial mediating role between the two.
\end{abstract}

\section{Introduction}

Sociologist Homans has made a more essential study of interpersonal relationships. In the social exchange theory, he reveals that all interpersonal relationships in society can be summarized as exchange relations. And the condition of harmonious and equal exchange relationship is to balance both sides in substance and spirit. Domestic scholar Sun Jianmin (2014) believed that organizations and employees are not simple employment or pure economic relationships, so these complex relationships between them can also be seen as social exchange relationships [1]. Liu Shanshi and Liu Xue (2008) believed that commitment-based human resource management practice is an important part of strategic human resource management. Compared to control-based human resource management practice, it focuses on individuals' value and worth [2]. From this perspective, it shows a strong sense of superiority.

For the study of employee satisfaction, there are rich results at home and abroad. Robbins (1998) concluded that five factors (the challenging work content, fair salary, good colleagues, supportive work environment and staff matching) can significantly enhance employee satisfaction [3]. Hu Bei (2003) pointed out that the factors affecting the job satisfaction of Chinese mental workers can be divided into three aspects: work environment, work content and relationship between colleagues [4]. Fang Zhitao (2019) studied the factors that affecting employee satisfaction by using multiple linear regression techniques, and divided the factors that affecting employee satisfaction into salary, welfare, work environment, interpersonal relationship and enterprise management [5]. A summary of the above literatures reveals that the diverse factors that influence employee satisfaction can match with different aspects of human resource management practices. Therefore, the implementation effect of human resource management practices can predict employee satisfaction to a certain extent.

At the same time, the implementation of human resource management practices is mostly related to the direct superior, that is, to the line leader. Li Rui and Tian Xiaoming (2014) believed that because of some restriction (such as span of management, personal ability and time), leaders could form different 
exchange relationships in the process of working with different employees. This relationship can directly affect the work of employees and are a key factor in the decision-making of employees ${ }^{[6]}$. Therefore, we found that the relationship between employees and leaders also affects employees' job satisfaction.

Combined with the above analysis, this paper will explore the impact of commitment-based human resource management practices on employee job satisfaction. Considering that different employees feel different sense of the organization's human resource management practices, so the quality of leader-member exchange relationship can explain the perceiving differences ${ }^{[7]}$. This paper try to consider the quality of LMX relationship as mediator in the influence mechanism between the commitment-based human resource management practices and employee satisfaction, and to find whether and to what extent it plays a mediating role.

\section{Research Hypothesis}

As an important part of strategic management, commitment-based human resource management practice aims to establish a stable and long-lasting exchange relationship with employees. Through human resource management practices, enterprises shape the good relationship between organization and employees. Thus, it can create harmonious working atmosphere and interpersonal relationship, and can enhance employees' sense of self-worth and satisfaction ${ }^{[8]}$. It can be sure that, through a series of management measures, commitment-based human resource management practices can effectively strengthen employees' organizational loyalty and commitment. With the purpose of researching the impact mechanism between commitment-based human resource management practices and employee innovation behavior, Zhang Ruijuan and Sun Jianmin (2014) investigated 658 employees from 100 companies, using cross-level analysis technology. And the results showed that the commitment-based human resource management practice has a positive impact on the job engagement ${ }^{[9]}$. Thus, we hypothesize:

Hypothesis 1: Commitment-based human resource management will be positively related to employee satisfaction.

Line leaders are the actual performers of organizational management practices and the recipients of employee feedback. Therefore, different management measures will affect the quality of the relationship between leaders and employees. Tian Jie (2016) takes 243 employees that from traditional manufacturing, high-tech and retail industries as the research object. Based on the perspectives of LMX and TMX, it proves that the leader-member exchange relationship played a mediating role between the commitment-based human resource management practices and anti-production behavior. And they also confirmed that the commitment-based human resource management practices can significantly improve the quality of the LMX relationship ${ }^{[10]}$.Thus, we hypothesize:

Hypothesis 2:Commitment-based human resource management will be positively related to leader-member exchange relationship.

The quality of the exchange relationship between the line leader and the employee will greatly affect the employee's satisfaction. Huang Xiangli (2013) used a sample survey method to obtain 187 teacher samples from a university in Central China. The structural equations were used to analyze the data. And the results showed that the exchange quality is positively related to overall job satisfaction, internal satisfaction and external satisfaction ${ }^{[11]}$. Thus, we hypothesize:

Hypothesis 3: Leader-member exchange relationship will be positively related to employee satisfaction.

Whether management practices can accurately and efficiently establish communication channels between organizations and employees has become a problem that cannot be ignored. How and to what extent employees build loyalty to the organization is also affected by employees' perception. To a certain extent, direct leaders are the actual implementers of organizational management practices. The quality of the leader-member relationship will affect the implementation of management measures, which in turn will affect 
employees' perception. So the process will be mediated by the LMX relationship, in this process the human resource management practices exerting influence on employee satisfaction. Thus, we hypothesize:

Hypothesis 4: Leader-member exchange relationship will play a mediating role.

\section{Data Analysis}

In this paper, we use the 10-item scale compiled by Xiao and Tsui (2011) to measure commitment-based human resource management practices. The measurement of the LMX relationship refers to the scale which revised by Wang Hui et al. (2005) and based on the foreign scholars' scale. The Minnesota Satisfaction Scale $(M S Q)$ is used for the measurement of job satisfaction.

A total of 119 samples were collected in this research. It can be seen from the basic situation statistics that the male-female ratio is somewhat out of balance. Female subjects are $19.32 \%$ higher than men; the age distribution is concentrated below 49 years old; the education level is mostly undergraduate; the distribution of unit scale was also relatively "U"-shaped distribution.

\section{Reliability and Validity Test}

First, the exploratory factor analysis method was used to observe the KMO value and the Bartlett spherical test result. When the KMO value is greater than 0.7 and the Bartlett spherical test result pass the significant level $(p>\alpha)$, it can be considered that the factor analysis could be used for factor analysis. The three scales in this paper are all tested by KMO and factor analysis can be performed. Among them, the commitment-based human resource management practices scale can extract three main factors: training and development, job autonomy, team work and performance appraisal (hereinafter respectively referred to as TD, JA and TP); four main factors can be extracted in the LMX relationship scale: emotional dimension, loyalty dimension, contribution dimension, professional respect (hereinafter respectively referred to as $E D$, $L D, C D$ and $P D$ ); employee satisfaction can extract four main factors, and the first four factors The cumulative interpretation variance ratio reached $65.876 \%$.

Based on exploratory factor analysis, we continue to use confirmatory factor analysis to test the structural validity of the scale. Observing values of the indexes (such as RMSEA, GFI, CFI and NFI), we confirmed that the goodness-of-fit results of the three scales were good, and each item converges well to the main factor extracted by exploratory factor analysis. So the validity of the scale is good.

We use the cloned Bach coefficient for reliability analysis. The values of Cronbach's alpha are more than 0.8 , and the values of Cronbach's alpha are above 0.85 . Therefore, it can be judged that the data can be used for further research.

\section{Correlation Analysis}

Before regression analysis, it is necessary to determine whether there is a certain correlation between variables. We use SPSS 20.0 to analyze the correlation among commitment-based human resource management practices (hereinafter referred to as CHMP), leader-member exchange (hereinafter referred to as $L M X$ ) and employee satisfaction (hereinafter referred to as $E S$ ).

It can be seen from the Table 1 that the correlation between the variables is proved at the level of 0.01 , which provides preconditions for the hypothesis of 1,2 and 3. 
Table 1 Correlation Analysis

\begin{tabular}{|c|c|c|c|c|c|c|c|c|c|c|}
\hline Variable & 1 & 2 & 3 & 4 & 5 & 6 & 7 & 8 & 9 & 10 \\
\hline CHMP & 1 & & & & & & & & & \\
\hline TD & $.819^{*}$ & 1 & & & & & & & & \\
\hline JA & $.551^{*}$ & $.382^{*}$ & 1 & & & & & & & \\
\hline $\mathrm{TP}$ & $.789^{*}$ & $.642^{*}$ & $.471^{*}$ & 1 & & & & & & \\
\hline LMX & $.522^{*}$ & $.508^{*}$ & $.406^{*}$ & $.468^{*}$ & 1 & & & & & \\
\hline ED & $.547^{*}$ & $.524^{*}$ & $.418^{*}$ & $.491^{*}$ & $.756^{*}$ & 1 & & & & \\
\hline LD & $.348^{*}$ & $.376^{*}$ & $.322^{*}$ & $.319^{*}$ & $.712^{*}$ & $.529^{*}$ & 1 & & & \\
\hline $\mathrm{CD}$ & $.334^{*}$ & $.315^{*}$ & $.295^{*}$ & $.299^{*}$ & $.777^{*}$ & $.560^{*}$ & $.546^{*}$ & 1 & & \\
\hline PD & $.553^{*}$ & $.553^{*}$ & $.423^{*}$ & $.499^{*}$ & $.691^{*}$ & $.588^{*}$ & $.533^{*}$ & $.439^{*}$ & 1 & \\
\hline ES & $.514^{*}$ & $.551^{*}$ & $.500^{*}$ & $.457^{*}$ & $.633^{*}$ & $.574^{*}$ & $.504^{*}$ & $.482^{*}$ & $.577^{*}$ & 1 \\
\hline
\end{tabular}

\section{Regression Analysis}

As we can see from the Table 2, this paper performs 7 regressions on three variables and their sub-variables, and excludes non-significant variables. Model 2 shows that training and development ( $a$ sub-variable of commitment-based human resource management practices) is positively related to employee satisfaction; Model 7 shows that commitment-based human resource management practices have a positive correlation with leader-member exchange relationships; Model 4 indicates that the emotional dimension and professional respect have a positive impact on employee satisfaction. All the results above confirm the first three hypotheses.

Table 2 Regression Analysis

\begin{tabular}{|c|c|c|c|c|c|c|c|}
\hline \multirow{2}{*}{$\begin{array}{c}\text { Variable } \\
\text { Explaining Variable }\end{array}$} & \multirow{2}{*}{$\frac{\text { LMX }}{\text { Model } 7}$} & \multicolumn{6}{|c|}{ ES } \\
\hline & & Model 1 & Model 2 & Model 3 & Model 4 & Model 5 & Model 6 \\
\hline $\mathrm{TD}$ & $0.315^{*}$ & $0.255^{*}$ & $0.316^{*}$ & & & & \\
\hline TP & $0.165^{*}$ & 0.096 & & & & & \\
\hline $\mathrm{ED}$ & & & & $0.189^{*}$ & $0.262^{*}$ & & \\
\hline LD & & & & 0.044 & & & \\
\hline $\mathrm{CD}$ & & & & 0.114 & & & \\
\hline $\mathrm{PD}$ & & & & $0.178^{*}$ & $0.205^{*}$ & & \\
\hline Mediating Effect & & & & & & & \\
\hline CHMP & & & & & & $0.344^{* *}$ & $0.171^{* *}$ \\
\hline LMX & & & & & & & $0.353^{* *}$ \\
\hline $\mathrm{R}^{2}$ & 0.301 & 0.247 & 0.234 & 0.376 & 0.349 & 0.242 & 0.368 \\
\hline$\Delta \mathrm{R}^{2}$ & 0.289 & 0.234 & 0.228 & 0.354 & 0.338 & 0.236 & 0.358 \\
\hline
\end{tabular}

It can be seen from the test results of Model 5 in the above table that when the commitment-based human resource management practice is the only independent variable of employee satisfaction, the regression coefficient is 0.514 . When we introduce the LMX to carry on binary regression, the coefficients are notable but coefficient of commitment-based human resource management reduces to 0.253 . It can be judged that the LMX relationship plays a partial intermediary role between the commitment-based human resource management practices and employee satisfaction. Hypothesis 4 is verified.

\section{Conclusions and Suggestions}

\section{Conclusions}

On the one hand, the research results support the direct impact of commitment-based human resource management practices on employee satisfaction, especially in terms of training and development, job 
autonomy which have a significant positive impact on employee satisfaction. On the other hand, it also reveals that the commitment-based human resource management practice first affects the LMX relationship, and then the intermediary effect of the quality of LMX will have an impact on employee satisfaction.

\section{Suggestions}

Improve the traditional control-based human resource management practices system and establish a commitment-based human resource management concept. Control-based human resource management practices ignore the personal value of employees and fail to pay the necessary emotional attention to employees. In the long run, employees will feel burnout and tired of work or organization because they do not feel the emotional attention of the organization. Declining employee satisfaction could affect the performance of their work, which will have a negative impact on both the organization and individuals. Commitment-based human resource management practices can provide employees with personalized training methods, pay attention to the personal development of employees, give employees more space in terms of work autonomy and ultimately enhance employee satisfaction.

Strengthen the training and communication of frontline managers. Frontline managers are generally part of the organization and are directly in contact with grassroots employees. Since the implementation of management policies is largely done by direct leadership, the quality of policies implementation has a lot to do with the ability of leadership. "Good" leaders can flexibly build a benign relationship with different employees and can improve the quality of exchange relationships to enhance employee satisfaction. The organization should pay attention to this part of the staff and strengthen the training of its leadership ability so that the leader can pay attention to cultivation of relationships with employees. At the same time, communication with frontline managers should be strengthened to obtain more effective and true feedback information to improve management measures.

\section{References}

[1]ZHANG Ruijuan, SUN Jianmin, WANG Zhen.Relationship between Commitment Human Resource Management Practice, Staff Work Input and Innovation Behavior[J].Journal of Chongqing University(Social Science Edition),2014,20(04):73-79.

[2] Liu Shanshi, Liu Xue. The Best Human Resource Practice of Chinese Enterprises [J]. Science and Technology Management Research, 2008 (05): 199-201.

[3] Lai Lijuan. Research on the relationship between psychological contract, job satisfaction and turnover intention [D]. China University of Geosciences (Beijing), 2016.

[4] Hu Wei, Chen Jianan. Empirical Research on Job Satisfaction of Mental Workers[J]. Research Management, 2003(04): 139-144.

[5] Fang Zhitao. Employee Satisfaction Model Based on Multiple Linear Analysis[J]. Chemical Industry Management, 2019(10): 10-11.

[6] Duan Jinyun, Zhang Chen, Tian Xiaoming. The Mechanism of Employees' Behaviors: The Influence from Leaders[J]. China Human Resources Development, 2016(05): 16-26.

[7] Lin Yaqing, Zhao Yuming. Research on the Relationship between Perceived Commitment Human Resource Management and Staff Performance- - The Regulating Role of Organizational Trust[J].Nanjing Business Review,2014,11(01):203-218.

[8] He Jie, Ding Ningning, Wang Dongdong. The Impact of Commitment Human Resource Management Practice on Employee Engagement: An Integrated Perspective of Self-Decision and Social Exchange[J]. China Human Resources Development, 2015(13): 58-63. 
[9] Wang Zhen, Sun Jianmin. Human Resource Management Practice, Organizational Support and Employee Commitment and Recognition__A Cross-Level Study[J].Economic Management,2011,33(04):80-86.

[10] Tian Jie. Research on the Influence Mechanism of Commitment Human Resource Management Practice on Anti-production Behavior_—Based on the Perspective of LMX and TMX[J].Shopping Modernization, 2016(13):99-101.

[11] ZHOU Lizhen, HUANG Xiangli. Research on the Relationship between Organizational Citizenship Behavior and Leadership Exchange Quality[J]. Journal of Hunan Institute of Engineering (Social Science Edition), 2013, 23(02): 13-16. 